\title{
A hemizygous p.R204Q mutation in the ALAS2 gene underlies X-linked sideroblastic anemia in an adult Chinese Han man
}

Jinbo Huang, Meili Ge*, Yingqi Shao, Min Wang, Peng Jin, Jiali Huo, Xingxin Li, Jing Zhang, Neng Nie and Yizhou Zheng

\begin{abstract}
Background: X-linked sideroblastic anemia (XLSA) is the most common form of congenital sideroblastic anemia (CSA), and is associated with the mutations in the 5-aminolevulinate synthase 2 (ALAS2). The genetic basis of more than $40 \%$ of CSA cases remains unknown.

Methods: A two-generation Chinese family with XLSA was studied by next-generation sequencing to identify the underlying CSA-related mutations.

Results: In the study, we identified a missense ALAS2 R204Q mutation in a hemizygous Chinese Han man and in his heterozygous daughter. The male proband presented clinical manifestations at 38 years old and had a good response to pyridoxine.
\end{abstract}

Conclusions: XLSA, as a hereditary disease, can present clinical manifestations later in lives, for adult male patients with ringed sideroblasts and hypochromic anemia, it should be evaluated with gene analyses to exclude CSA.

Keywords: ALAS2, X-linked sideroblastic anemia, Hemizygous

\section{Background}

Congenital sideroblastic anemia (CSA) is a group of heterogeneous disorders characterized by hypochromic erythrocytes, increased serum iron and ferritin levels and bone marrow ringed sideroblasts [1,2]. X-linked sideroblastic anemia (XLSA) is the most common form of CSA, and is attributed to the 5-aminolevulinate synthase (ALAS2) mutations [2,3]. The human ALAS2 gene is mapped on the $\mathrm{X}$ chromosome $[4,5]$, and encodes

\footnotetext{
*Correspondence: gemeili@ihcams.ac.cn

State Key Laboratory of Experimental Hematology, National Clinical Research Center for Blood Diseases, Institute of Hematology and Blood Diseases Hospital, Chinese Academy of Medical Science and Peking Union Medical College, 288 Nanjing Road, Tianjin 300020, People's Republic of China
}

erythroid-specific $A L A S 2$, which catalyzes the first and rate-limiting steps in the heme biosynthesis pathway in erythroid cells. According to the literatures since 2011 and Human Gene Mutation Data Base, over 100 missense mutations in the $A L A S 2$ gene have now been reported on XLSA patients.

Here, we report a missense mutation in the ALAS2 gene in an adult male XLSA patient and his daughter.

\section{Materials and methods \\ Patient}

One patient with anemia was referred to the Institute of Hematology and Blood Diseases Hospital, CAMS and PUMC, Tianjin, China in December 2019, and was diagnosed as XLSA. His son and daughter also participated 
in the study. Written informed consents were obtained from the participant or the parents of the participants under the age of 18 . The study was approved by the Ethics Committees of the Institute of Hematology, CAMS and PUMC (Ethics number: KT2017031-EC-1).

\section{Next-generation sequencing (NGS)}

Genetic testing for hereditary blood and immune system diseases (including 700 genes) was performed in a panel by NGS. According to the standard procedure, a customcrafted capture array (Nimblegen Sequence Capture array, Roche, USA) was used to capture all exons, splice sites, and the flanking intron sequences of all associated genes. SOAPsnp and Samtools pileup softwares were used to analyze gene mutation.

\section{Confirmation of candidate mutation by Sanger sequencing} The corresponding ALAS2 gene region surrounding the R204Q mutation was amplified by PCR and sequenced by Sanger sequencing. PCR amplifications were performed in an ABI Veriti. Sequences were loaded on an ABI3500XL (Applied Biosystems). The sequence data files were analyzed using both Sequencing Analysis 5.2 and Variant Reporter v 1.1 software (Applied Biosystems). The primers for validating ALAS2 R204Q mutation were as follows:

Forward primer: $5^{\prime}$ TTTTCATCCTCATATCTGCTC CTG 3'.

Reverse primer: $5^{\prime}$ TTGCTTGGTCTCCCATCC TTC3'.

\section{Results}

Three individuals from a two-generation family were enrolled for the study, including the proband (II-1, 38 years), his healthy son (III- 1,12 years) and asymptomatic carrier daughter (III-2, 14 years) (Fig. 1a).

\section{Clinical findings}

The patient, a 38-year-old Han Chinese male, lost contact with his biological parents and was brought up by foster

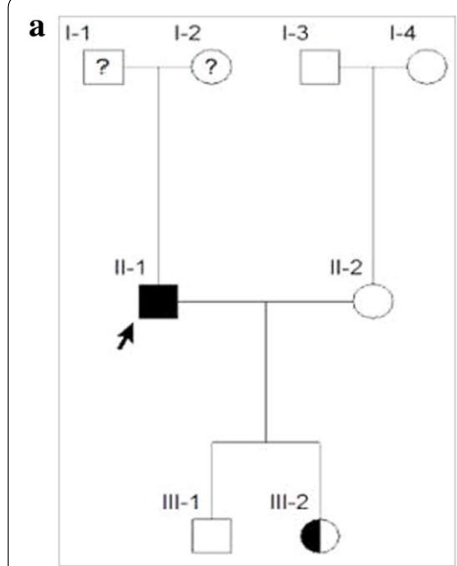

c

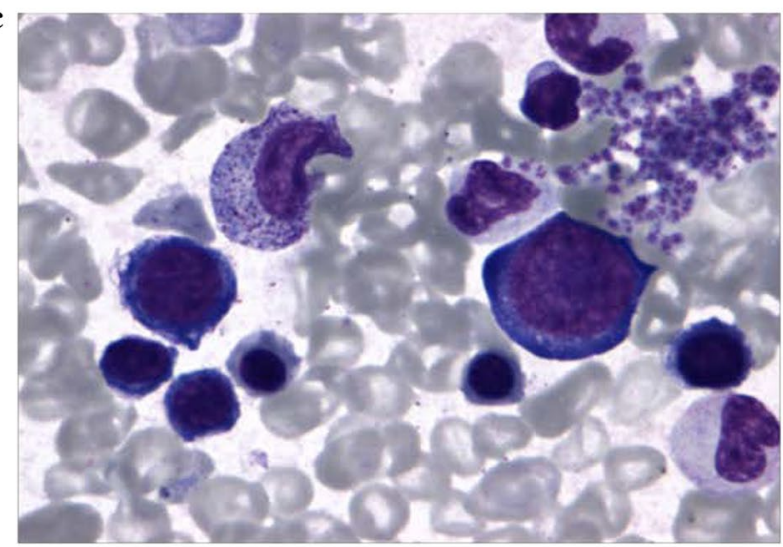

b

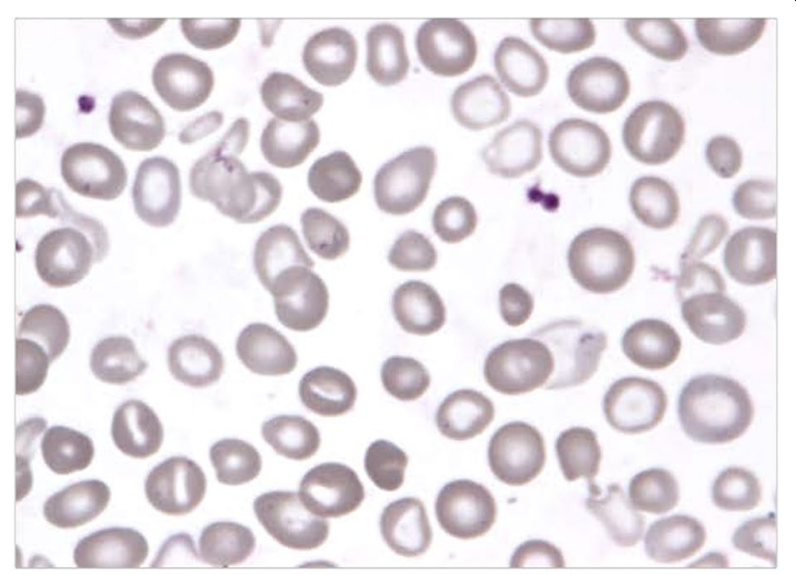

d

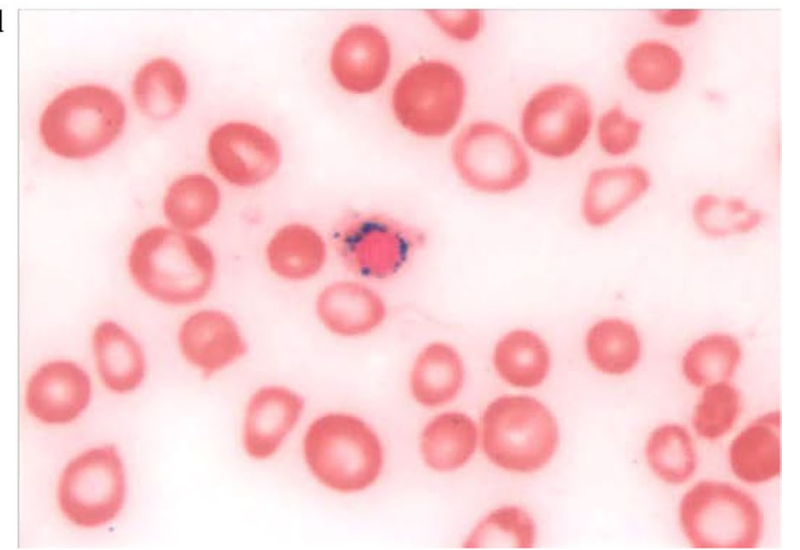

Fig. 1 a Pedigree of a Chinese family with XLSA, the arrow indicated the proband. $\mathbf{b}$ The peripheral blood film from proband showed microcytic hypochromic, normocytic, and normochromic erythrocytes (HE stain, $\times 400$ ). c The bone marrow film from proband showed mild dyserythropoietic change (HE stain, $\times 400)$. $\mathbf{d}$ The Prussian blue-stained specimens of bone marrow film from proband showed ringed sideroblasts with multiple perinuclear iron granules (HE stain, $\times 400$ ) 
parents. He was admitted to our hospital with a 2-month history of fatigue. He had normal stature and skin color, no hepatosplenomegaly. The red blood cell (RBC) counts were as follows: RBCs $4.53 \times 10^{12} / \mathrm{L}$ (reference value: 4.0-5.5 $\times 10^{12} / \mathrm{L}$ ), hemoglobin $(\mathrm{Hb}) 91 \mathrm{~g} / \mathrm{L}$ (reference value: $120-160 \mathrm{~g} / \mathrm{L})$, mean corpuscular volume (MCV) 74.2fL (reference value: 80-100 fL), mean corpuscular hemoglobin concentration (MCHC) $271 \mathrm{~g} / \mathrm{L}$ (reference value: $320-360 \mathrm{~g} / \mathrm{L}$ ), red blood cell distribution width (RDW) 31.8\% (reference value: 11.1-14.1\%), Reticulocyte (RET) rate $2.87 \%$ (reference value: $0.5-1.5 \%$ ). The peripheral blood film was dimorphic, including microcytic hypochromic, normocytic, and normochromic erythrocytes (Fig. 1b). Ferritin was $625.9 \mathrm{ng} / \mathrm{mL}$ (reference range: $23.9-336.2 \mathrm{ng} / \mathrm{mL}$ ). Thalassemia gene test was negative. Bone marrow analysis revealed marked erythroid hyperplasia with mild dyserythropoietic changes (Fig. 1c). The ringed sideroblasts with multiple perinuclear iron granules constituted over $40 \%$ of total erythroblasts in the Prussian blue-stained specimens (Fig. 1d). The RBC counts of the patient's asymptomatic carrier daughter were as follows: RBCs $4.80 \times 10^{12} / \mathrm{L}, \mathrm{Hb} 127 \mathrm{~g} / \mathrm{L}, \mathrm{MCV}$ $82.0 \mathrm{fL}, \mathrm{MCHC} 321 \mathrm{~g} / \mathrm{L}, \mathrm{RDW} 14.1 \%$.

Oral pyridoxine $(60 \mathrm{mg}$, three times a day) was prescribed to the XLSA patient with ALAS2 p.R204Q mutation, $\mathrm{Hb}$ rose to $149 \mathrm{~g} / \mathrm{dL}$ after 3 months course and remained normal at the 9-month follow-up. However, erythrocytes still showed microscopic and hypochromic, with little improvement. The patient didn't receive iron chelation therapy. Ferritin was $885.6 \mathrm{ng} / \mathrm{mL}$ after 6 months, and $957.9 \mathrm{ng} / \mathrm{mL}$ after 9 months.

\section{Genetic findings}

We detected a missense mutation for a $\mathrm{G}$ to A transition in exon 5 of the ALAS2 gene, which caused a arginine (Arg) to glutamine (Gln) substitution at amino acid position 204 (NM_000032.5: c.611G>A; p.R204Q) in the proband and his daughter (Fig. 2a, c), which located at the domains important for pyridoxal phosphate co-factor binding $[6,7]$. His son (III-1) was normal (Fig. 2b). Different predictive tools were used to determine the significance of the missense mutation: Polyphen-2 (the

a

\section{ALAS2: c. $611 \mathrm{G}>\mathrm{A}$ hemizygous missense mutation}

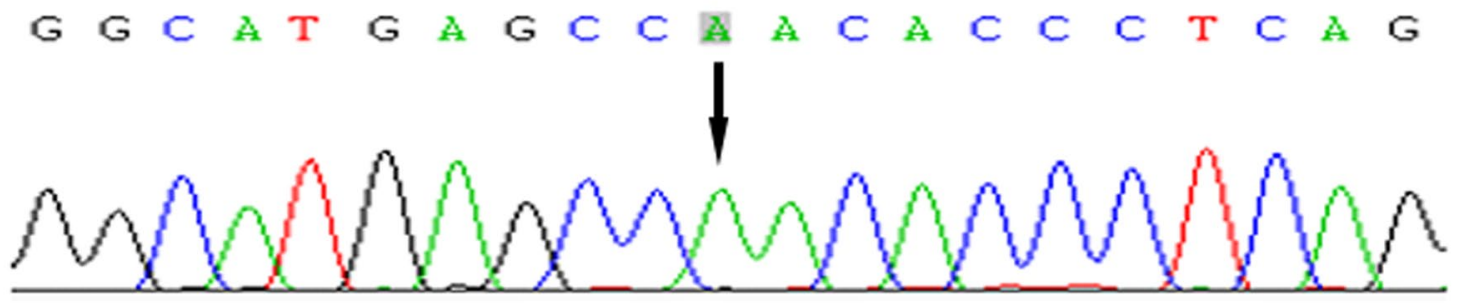

b

ALAS2: no mutation at c.611 (III-1)

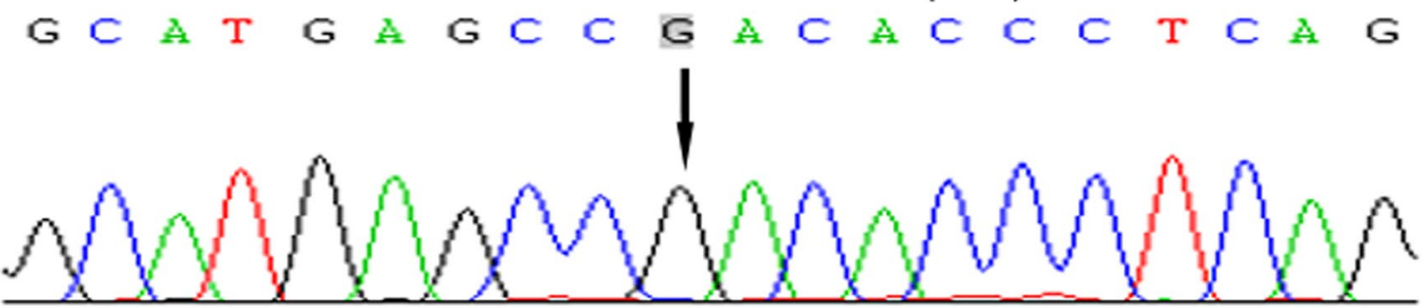

c

ALAS2: c. $611 \mathrm{G}>\mathrm{A}$ heterozygous missense mutation

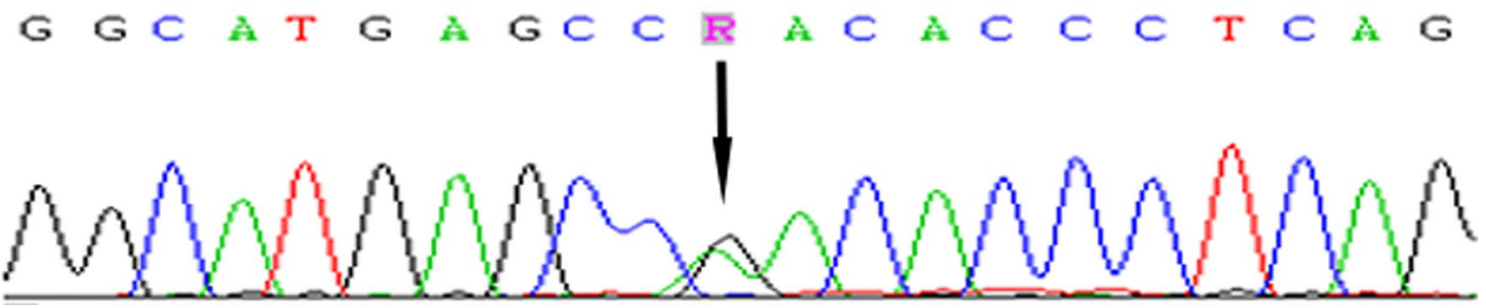

Fig. 2 a A hemizygous mutation (c.611G>A; p.R204Q) in the proband with XLSA. b The proband'son had no mutation at C.611. c The proband' daughter harbored a heterozygous mutation (c.611G >A; p.R204Q) 
mutation was predicted to be "possibly damaging" with a score of 0.673) (http://genetics.bwh.harvard.edu/ggi/ pph2/69eced31378726308ea4c615c8598d621e117817/ 6950834.html), PROVEAN (the mutation was predicted to be "deleterious" with a score of -2.72) and SIFT(the mutation was predicted to be "tolerated" with a score of 0.497) (http://provean.jcvi.org/protein_batch_view_ table.php?jobid=798947818062689). The results suggested that this substitution had a moderate probability for affecting the protein function.

\section{Discussion}

We found an ALAS2 missense mutation (p.Arg204Gln) in a hemizygous adult man and in his heterozygous daughter. The mutation has already been reported $[8,9]$. The reported male patient presented clinical manifestations at 38 years old, with ringed sideroblasts and microscopic hypochromic anemia. In adults, ringed sideroblasts are commonly associated with MDS, and often result from splicing factor $3 \mathrm{~b}$, subunit 1 (SF3B1) mutation [10]. However, because mild, life-long anemia may not be detected because of lack of symptoms, asymptomatic subjects are discovered through routine blood examination or family surveys, some XLSA patients can present clinical manifestations later in their lives. The oldest reported case was an 81-year-old male who suffered with chronic renal failure, pyridoxine deficiency caused by maintenance hemodialysis therapy resulted in obvious anemia and uncovered occult inherited enzymatic deficiencies [11]. Recently, another late-onset XLSA also had been reported [12]. A few reports had described the misdiagnosis of adult patients with XLSA as MDS with refractory anemia with ringed sideroblasts (MDS-RARS) [13]. In addition, women with XLSA nearly always have normocytic or macrocytic anemia that has to be distinguished from MDS-RARS, they develop symptomatic XLSA later in life due to acquired skewing of $\mathrm{X}$ chromosome inactivation in hematopoietic cells leading to predominance of an active $\mathrm{X}$ which bears an ALAS2 mutation. XLSA and MDS-RARS have the shared morphological features, such as the dyserythropoiesis and ringed sideroblasts, so it may be required to exclude XLSA by the identification of the ALAS2 mutation.

$A L A S 2$ catalyzes the first step of heme biosynthetic pathway by condensing glycine and succinyl-CoA to form delta-aminolevulinic acid in the presence of a pyridoxal 5'-phosphate, which is the metabolite of vitamin B6 [14]. In the process of ALA synthesis, PLP is a cofactor reversibly bound to Lysine 391 and its binding is absolutely required for enzymatic activity [15]. All reported ALAS2 mutations in male XLSA patients were missense mutations, mostly located at the domains important for pyridoxal phosphate co-factor binding or catalysis $[6,7]$.
Pyridoxine can enhance the activity of ALAS2 enzyme, more than half of XLSA patients have response to pyridoxine [1]. Our reported ALAS2 mutation (p.Arg204Gln) is located on the surface of the ALAS2 3D structure some distance from the PLP moiety that is buried in the middle of the structure [6]. We can only speculate that the presence of Gln at the R204 location destabilizes the enzyme's structure but the binding of the PLP cofactor stabilizes the mutant structure somewhat. Consistent with this line of reasoning, others have shown that this mutant enzyme's activity was only $15.1 \%$ of that of the normal control but could be increased up to $34.5 \%$ with the addition of pyridoxine [8]. This finding was confirmed by the good response to pyridoxine treatment observed for the proband in our study.

CSA patients are prone to iron overload, whether pyridoxine-responsive or not, regardless of red blood cell transfusions. Iron overload is partly attributed to reduced hepcidin level secondary to ineffective erythropoiesis which promotes intestinal iron absorption [16]. Our reported XLSA patient had no red blood cell transfusion and had a good response to pyridoxine, the ferritin still increased gradually, iron depletion by phlebotomy should be initiated if serum ferritin is over $1000 \mathrm{mcg} / \mathrm{L}$.

\section{Conclusions}

In summary, we identified an X-linked ALAS2 R204Q mutation in a hemizygous Chinese Han man and in his heterozygous daughter. The male patient showed clinical presentation at the adult age. It should be evaluated with gene analyses to exclude CSA for adult male patients with ringed sideroblasts and microscopic hypochromic anemia.

\section{Abbreviations \\ ALAS2: 5-Aminolevulinate synthase; CSA: Congenital sideroblastic anemias; FL: Flt3 ligand; IL-3: Interleukin-3; Hb: Hemoglobin; MCHC: Mean corpuscular hemoglobin concentration; MCV: Mean corpuscular volume; MDS: Myelo- dysplastic syndrome; MDS-RARS: MDS with refractory anemia with ringed sideroblasts; TPO: Thrombopoietin; RBCs: Red blood cells; RET: Reticulocyte; SF3B1: Splicing factor 3b, subunit 1; SCF: Stem cell factor; XLSA: X-linked sideroblastic anemia.}

\section{Supplementary Information}

The online version contains supplementary material available at https://doi. org/10.1186/s12920-021-00950-x.

Additional file1: Data title: the ALAS2 sequence of the proband, his daughter and son by Sanger sequencing

\section{Acknowledgements}

We would like to thank the family members for their involvement in this study. The authors thank all of the doctors and nurses in Therapeutic Centre of Anemic Diseases and the researcher team of Clinical Laboratory Centre for their professional assistance. 


\section{Authors' contributions}

JH1, MG, YS and MW carried out family recruitment, blood sampling and clinical analysis. JH1, PJ, JH2 and $Y Z$ conceived and designed the experiments. JH1, $\mathrm{JZ}$ and $\mathrm{XL}$ performed the experiments. $\mathrm{NN}$ and $\mathrm{JH} 1$ analyzed the data. JH1, MG and $Y Z$ wrote the paper. All authors read and approved the final manuscript.

\section{Funding}

This work was supported by a grant from the National Natural Science Foundation of China (No.81770119).

\section{Availability of data and materials}

The sequence of ALAS2 gene tested by Sanger sequencing used and/or analyzed during the current study are available in the Additional file 1. All other data generated or analysed in this study were included in this article.

\section{Declarations}

\section{Ethics approval and consent to participate}

This study was approved by the Ethics Committees of the Institute of Hematology, CAMS and PUMC (Ethics number: KT2017031-EC-1). Written informed consent to participate was obtained from all of the participants in the study. Written informed consent to participate was obtained from the parents of the patients under the age of 18 .

\section{Consent for publication.}

Written informed consents for publication of clinical details and images were obtained from participant and the parents of the participants under the age of 18 .

\section{Methods}

All methods used during the current study were carried out in accordance with relevant guidelines and regulations.

\section{Competing interests}

The authors declare that they have no competing interests.

Received: 11 November 2020 Accepted: 23 March 2021

Published online: 15 April 2021

\section{References}

1. May A, Bishop DF. The molecular biology and pyridoxine responsiveness of X-linked sideroblastic anaemia. Haematologica. 1998;83:56-70.

2. Bottomley SS, Fleming MD. Sideroblastic anemia: diagnosis and management. Hematol Oncol Clin North Am. 2014;28:653-70.

3. Percy MJ, Cuthbert RJG, May A, McMullin MF. A novel mutation, lle289Thr, in the ALAS2 gene in a family with pyridoxine responsive sideroblastic anaemia. J Clin Pathol. 2006;59(9):1002.

4. Cotter PD, Willard HF, Gorski JL, Bishop DF. Assignment of human erythroid delta-aminolevulinate synthase (ALAS2) to a distal subregion of band Xp11.21 by PCR analysis of somatic cell hybrids containing $X$; autosome translocations. Genomics. 1992;13(1):211-2.

5. Cox TC, Bawden MJ, Abraham NG, Bottomley SS, May BK, Baker E, Chen $\mathrm{LZ}$, Sutherland GR. Erythroid 5-aminolevulinate synthase is located on the X chromosome. Am J Hum Genet. 1990;46(1):107-11.
6. Bailey H, Bezerra GA, Marcero JR, Padhi S, Foster WR, Rembeza E, Roy A, Bishop DF, Desnick RJ, Bulusu G, Dailey HA, Yue WW. Human aminolevulinate synthase structure reveals a eukaryotic-specific autoinhibitory loop regulating substrate binding and product release. Nat Commun. 2020;11(1):2813.

7. Astner I, Schulze JO, van den Heuvel J, Jahn D, Schubert WD, Heinz DW. Crystal structure of 5-aminolevulinate synthase, the first enzyme of heme biosynthesis, and its link to XLSA in humans. Embo J. 2005;24(18):3166-77.

8. Harigae H, Furuyama K, Kudo K, Hayashi N, Yamamoto M, Sassa S, Sasaki T. A novel mutation of the erythroid-specific gamma-Aminolevulinate synthase gene in a patient with non-inherited pyridoxine-responsive sideroblastic anemia. Am J Hematol. 1999;62(2):112-4.

9. Méndez M, Moreno-Carralero M-I, Morado-Arias M, Fernández-Jiménez M-C, de la Iglesialñigo S, Morán-Jiménez M-J. Sideroblastic anemia: functional study of two novel missense mutations in ALAS2. Mol Genet Genomic Med. 2016;4(3):273-82.

10. Yoshida K, Sanada M, Shiraishi Y, Nowak D, Nagata Y, Yamamoto R, Sato Y, Sato-Otsubo A, Kon A, Nagasaki M, Chalkidis G, Suzuki Y, Shiosaka M, Kawahata R, Yamaguchi T, Otsu M, Obara N, Sakata-Yanagimoto M, Ishiyama K, Mori H, Nolte F, Hofmann WK, Miyawaki S, Sugano S, Haferlach C, Koeffler HP, Shih LY, Haferlach T, Chiba S, Nakauchi H, Miyano S, Ogawa S. Frequent pathway mutations of splicing machinery in myelodysplasia. Nature. 2011;478:64-9.

11. Furuyama K, Harigae H, Kinoshita C, Shimada T, Miyaoka K, Kanda C, Maruyama Y, Shibahara S, Sassa S. Late-onset X-linked sideroblastic anemia following hemodialysis. Blood. 2003;101(11):4623-4.

12. Fujiwara T, Fukuhara N, Ichikawa S, Kobayashi M, Okitsu Y, Onishi Y, Furuyama $\mathrm{K}$, Harigae $\mathrm{H}$. A novel heterozygous ALAS2 mutation in a female with macrocytic sideroblastic anemia resembling myelodysplastic syndrome with ring sideroblasts: a case report and literature review. Ann Hematol. 2017;96(11):1955-7.

13. Cotter PD, May A, Fitzsimons EJ, Houston T, Woodcock BE, Al-Sabah Al, Wong L, Bishop DF. Late-onset X-linked sideroblastic anemia. Missense mutations in the erythroid delta-aminolevulinate synthase (ALAS2) gene in two pyridoxine-responsive patients initially diagnosed with acquired refractory anemia and ringed sideroblasts. J Clin Invest. 1995;96(4):2090-6.

14. Shoolingin-Jordan PM, Al-Daihan S, Alexeev D, Baxter RL, Bottomley SS, Kahari ID, Roy I, Sarwar M, Sawyer L, Wang S-F. 5-Aminolevulinic acid synthase: mechanism, mutations and medicine. Biochim Biophys Acta. 2003;1647:361-6

15. Cazzola M, Malcovati L. Diagnosis and treatment of sideroblastic anemias: from defective heme synthesis to abnormal RNA splicing. Hematology Am Soc Hematol Educ Program. 2015;2015:19-25.

16. Furuyama K, Kaneko K. Iron metabolism in erythroid cells and patients with congenital sideroblastic anemia. Int J Hematol. 2018;107(1):44-54.

\section{Publisher's Note}

Springer Nature remains neutral with regard to jurisdictional claims in published maps and institutional affiliations.

Ready to submit your research? Choose BMC and benefit from:

- fast, convenient online submission

- thorough peer review by experienced researchers in your field

- rapid publication on acceptance

- support for research data, including large and complex data types

- gold Open Access which fosters wider collaboration and increased citations

- maximum visibility for your research: over 100M website views per year

At BMC, research is always in progress.

Learn more biomedcentral.com/submissions 